\title{
História da Educação: ego-documento de um pesquisador em terras paranaenses
}

\section{History of education: egodocument of a researcher in the lands of Paraná}

\author{
Marcus Levy Bencostta*
}

\begin{abstract}
RESUMO
Este ensaio apresenta a trajetória profissional do autor como parte dos requisitos do concurso de professor titular na disciplina História da Educação da Universidade Federal do Paraná, realizado no ano de 2015. O texto foi organizado de modo a facilitar a leitura, sem as amarras de uma narrativa marcada pelo formalismo, própria de um processo avaliativo. Dividido em tramas que apresentam, desde a formação universitária até aquelas que envolvem as atividades próprias da docência, assim como da pesquisa, da extensão e da administração. O objetivo é apresentar como se deu a construção da contribuição do autor para o campo da História da Educação.

Palavras-chave: História da Educação. Memorial. Ego-documento.
\end{abstract}

\begin{abstract}
This essay presents the author's professional trajectory as part of the requirements of the full professor selection process for the discipline of History of Education of the Federal University of Paraná, conducted in 2015. The text was organized in such a way as to facilitate reading without the marks of formalism characteristic of an evaluation process. Divided in threads that go from the university formation to those that involve the activities of teaching, and also of research, extension and administration, this essay aims to present the construction of the author's contribution to the field of history of education.
\end{abstract}

Keywords: History of education. Memorial. Egodocument.

* Universidade Federal do Paraná. Setor de Educação. E-mail: marcus@ufpr.br. https:// orcid.org/0000-0003-3387-7901. 
O objetivo desse documento autobiográfico é apresentar dados relevantes da minha trajetória acadêmica, profissional e intelectual até a conquista do título de professor titular em História da Educação da Universidade Federal do Paraná (UFPR), no ano de 2015.

Para tanto, utilizarei narrativas de lembranças documentadas, sem a presunção de construir verdades objetivas despossuídas de subjetividades, que indicam interpretações que tentam explicar minha própria compreensão dos anos dedicados à UFPR. Assim, o ângulo que sugiro ao leitor é ter-me como eu-autor de posse de narrativas que intentam em forma de palavras transmitir conteúdos de momentos que considero relevantes para esse tipo de relato. Sob este prisma, peço licença aos leitores para explicar que a tessitura dessa narrativa está repleta de informações decodificadas e fragmentadas de uma história pessoal, de um eu responsável pela construção de relatos de experiências em si.

Mas como posso definir de modo mais preciso este escrito como uma narrativa de algo vivido? Como tentar explicar a vivência acadêmica numa relação entre o geral e o particular? Primeiro, é fundamental que os leitores reconheçam o desafio que tive enquanto eu-autor ao enfrentar a tarefa de apaziguar a tensão entre o sujeito do enunciado e o da enunciação, ambos responsáveis pela explicação do relato autobiográfico. Segundo, é preciso considerar que o estranhamento provocado pela tensão do eu-autor que enuncia a sua própria experiência, colocou em cena a autocompreensão de sua autorrepresentação que procurou fugir de um mero relato curricular de atividades acadêmicas. $\mathrm{O}$ eu-autor tentou fazer dessa volta em si um exercício de escrita, como fiz em um escrito autobiográfico anterior; por isso, continuo acreditando que trata de uma narrativa tal qual "uma pequena fresta de uma janela semiaberta que permite a passagem de uma enternecida corrente de recordações vivas em minhas lembranças" (BENCOSTTA, 2011, p. 179).

Mas bem antes de chegar a terras paranaenses, acredito que tinha encontrado minha vocação para docência nos bancos do curso de História da Universidade Estadual de Campinas (UNICAMP), que me ensinou a entender a função social do professor em uma sociedade que se redemocratizava, após longos anos de luta contra a ditadura militar. Ainda em Campinas (SP), atuei no ensino fundamental e médio, oportunidade que desenvolvi habilidades professorais e, principalmente, confirmação da minha convicção pela carreira docente.

Durante a graduação fui monitor de disciplinas ministradas por docentes do curso, tais como a professora Leila Mezan Algranti (História do Brasil Monárquico) e o professor José Roberto do Amaral Lapa [In memoriam] (História do Brasil Republicano). Com este último tive a oportunidade de desenvolver meu primeiro projeto de iniciação científica financiado pela Fundação de Amparo à 
Pesquisa do Estado de São Paulo (FAPESP) com o tema da presença protestante no Brasil da primeira metade do século XIX.

Hoje, amadurecido, entendo melhor a importância daqueles anos de formação e como as oportunidades que vivenciei foram fundamentais para definir minha carreira ao transitar com importantes referências do mundo da investigação acadêmica nas Ciências Humanas. Fruto dessa experiência foi meu ingresso na tradicional e respeitada Universidade de São Paulo (USP) para realizar os cursos de mestrado e doutorado no seu conceituado e concorrido Programa de Pós-Graduação em História Social, quando fui novamente selecionado para ser bolsista da FAPESP. Em 1994, defendi a dissertação intitulada: "Protestantes em Campinas: a história de um colégio de confissão presbiteriana (1869-1892)”, sob a orientação de Augustin Wernet (In memoriam). Ao concluir esse trabalho fui convidado a publicá-la em forma de livro com o selo do Centro de Memória da UNICAMP.

Em 1999, conquistei o título de doutor em História com a tese: "Igreja e Poder em São Paulo: D. João Batista Correia Nery e a romanização do catolicismo brasileiro (1908-1920)", com o mesmo orientador do mestrado. O tema de escolha tratou das relações de poder da Igreja Católica brasileira com o Estado republicano, tomando como referência a ação pastoral e educacional da gestão do primeiro bispado da cidade de Campinas, no início do século XX.

Antes da finalização do doutorado, em dezembro de 1996, iniciei a carreira como docente e pesquisador da Universidade Federal do Paraná. No processo seletivo, conquistei o primeiro lugar do concurso público para a disciplina História da Educação, desde então atuo nessa disciplina.

Nos primeiros anos de trabalho na UFPR, em 2000, ajudei com outros colegas a fundar a Linha de Pesquisa História e Historiografia da Educação no Programa de Pós-Graduação em Educação. Momento em que assumi a liderança do Grupo de Pesquisa registrado no Diretório do CNPq "História da Educação, Instituições, Intelectuais e Culturas Escolares no Paraná (Séculos XIX-XX)”; a partir de 2001, tornei-me Bolsista de Produtividade em Pesquisa do CNPq.

Em 2004, ao ser selecionado como bolsista do Conseil International des Études Canadiennes (CIEC), realizei curso de aperfeiçoamento na Université du Québec à Montreal (Canadá) em convênio com o Centre Canadien d'Architecture (CCA) para desenvolver a pesquisa intitulada: "Architecture et Histoire: la culture scolaire au Canadá et au Brésil (1900-1930)”. Dando continuidade ao aprimoramento intelectual em anos posteriores, 2007-2008, realizei estudos de pós-doutoramento na qualidade de bolsista da CAPES na École Nationale Supérieure d'Architecture de Versailles (França); sendo albergado pela Profa. Dra. Anne-Marie Chatêlet no Laboratoire de Recherche Histoire Architecturale et Urbaine - Sociétés (LADRHAUS), local que tive 
a oportunidade de aprofundar a pesquisa intitulada "História da Educação e Arquitetura: por uma tipologia acerca do espaço da escola elementar (Brasil e França, 1870-1930)".

Quanto à pesquisa, os temas dos projetos que coordenei mantiveram sintonia com as investigações identificadas com o campo da História da Educação. Dentre eles, destaco aqueles que tenho profundo respeito e carinho pelos resultados alcançados, tais como A imagem fotográfica no estudo das instituições educacionais: os grupos escolares de Curitiba (1903-1971). Nessa investigação, desenvolvida com o apoio do Conselho Nacional de Desenvolvimento Científico e Tecnológico (CNPq), entre os anos de 2003-2006, os resultados de pesquisa apresentados em encontros, congressos, conferências e publicações - partiram da defesa que as fotografias escolares possuem um caráter relativo que perpassa a sua própria iconicidade. Por não remeter somente a um objeto possivelmente real, mas também a um objeto necessariamente real, a fotografia seria uma emanação do referente e testemunha de um "aconteceu assim". Assim, entendia e entendo que não seria a expressão fotográfica um mero reflexo ou reprodução fiel da realidade, mas uma mediação inserida em um contexto de experiência que dialoga com a memória. No caso das fotografias escolares, a representação do mundo me possibilitou enxergá-las enquanto documento/monumento portadoras de um sistema diverso de signos que contribuíram na percepção e, consequente, compreensão do passado histórico dos grupos escolares na cidade de Curitiba.

Dentre as inúmeras possibilidades de conhecer o universo escolar utilizando o suporte imagético da fotografia, uma cena que insistentemente me perturbava, no sentido provocativo, para o aprofundamento investigativo, era o tema da arquitetura e do espaço escolar. Foi naquele momento que me aproximei desse campo, responsável por demarcar minha trajetória como pesquisador até os dias de hoje.

Foi à procura de novas questões teóricas e empíricas que iniciei o projeto "História da Educação, Arquitetura e Espaço Escolar: os Grupos Escolares de Curitiba (1903-1950). E durante os anos de 2006 a 2009, também como o apoio do CNPq, minha maior inquietude naquele momento era entender como a construção de edifícios específicos para a escola graduada foi uma preocupação das administrações públicas que tinham no urbano o espaço privilegiado para a sua edificação. Como, em regra geral, a localização dos edifícios escolares deveria funcionar como ponto de destaque na cena urbana, foi possível compreender como a arquitetura e a configuração do espaço das primeiras construções de grupos escolares na cidade de Curitiba passaram a contribuir na elaboração de representações sociais para uma gramática discursiva arquitetônica que enaltecia o novo regime. Enxerguei nas fotografias dos edifícios, plantas arquitetônicas e demais fontes como matéria do conhecimento da realidade histórica, por 
dar a conhecer, quando problematizadas, uma evidência visual no sentido de pertencer comumente a um estágio de proposições que não são as primeiras no aspecto lógico, despertando lembranças de um passado que se aproxima de uma representação de memória coletiva sobre o universus scholaris do Brasil, que naquele estudo fez referência à escola primária graduada e pública.

Instigado pelo meu interesse na pesquisa em história da arquitetura escolar brasileira, iniciei, em 2008, um novo desafio investigativo que tratava do " $O$ discurso arquitetural de Cândido de Abreu: prefeito e arquiteto de Curitiba". Nesse projeto minhas atenções estavam voltadas para as ações de Cândido de Abreu, considerado o primeiro urbanista da cidade de Curitiba. Ele ficou mais conhecido por seus projetos de construção de praças e jardins, solares e edifícios públicos e, pouco menos, como autor do projeto de construção do edifício do Grupo Escolar Dr. Xavier da Silva, inaugurado solenemente no final de 1903. Nesta investigação procuro demonstrar por meio de pesquisa histórica as principais referências arquiteturais desse engenheiro como suporte de compreensão de uma cultura urbana e escolar que toma como exemplo o edifício do primeiro grupo escolar do estado do Paraná.

Ao encaminhar o relatório final dessa pesquisa ao $\mathrm{CNPq}$, destaquei a importância dos estudos acerca da arquitetura para a pesquisa histórica e como eles são capazes de demonstrar que a gramática espacial se insere no tempo, assim como o edifício se insere em um espaço. Tempo e espaço dialogam com as transformações do tecido urbano e, mais proximamente, com as políticas e interesses que determinam sua construção. No caso da arquitetura escolar, considerei como os discursos arquiteturais repercutiam diante das concepções de escola, pensados por arquitetos e autoridades de ensino, procurando, na medida do possível, verificar tipologias adotadas por certas correntes artísticas e culturais com o objetivo de identificar modos construtivos, elementos decorativos e programas iconográficos, e sua relação com os modos pedagógicos sobre o espaço escolar.

Um ponto que gostaria de destacar foi o encontro que tive com a concepção teórica denominada arquiteturologia (architecturologie), elaborada por Philippe Boudon $(2001,2003)$, que nos leva a pensar a arquitetura como pensamento do espaço da linguagem que expressa o conhecimento teórico da arquitetura. Por essa teoria entendi que a criação dos projetos de Cândido de Abreu foi fortemente influenciada pela relação que ele estabeleceu entre a sua capacidade de compreensão dos modelos arquiteturais vigentes de sua preferência e as dimensões dos edifícios instalados no espaço real. Nessa perspectiva, considerei que os espaços que ele projetou (residenciais, públicos e escolares) apresentam similitude à parte do espaço de concepção explicada e determinada pela modelização arquiteturológica, qual seja, foi a arquiteturologia responsável por tornar visível 
a todos o espaço de concepção de modo que o edifício fosse interpretado como resultado real de hipóteses, pensamentos e ideias decorrentes de seu contexto de criação, aquele onde é delimitado a experiência do objeto arquitetônico.

Nos últimos anos, um novo salto foi dado no sentido de investigar fenômenos que interferiram na arquitetura escolar moderna, quando iniciei, em 2013, o projeto de pesquisa, ainda em andamento no CNPq, que trata da " $A$ Linguagem da Bauhaus e a gramática arquitetural escolar moderna (1919-1933)”. Foi em uma ambiência de construtos teóricos já defendidos por mim em diversos escritos (BENCOSTTA, 2001; 2005; 2006; 2007a; 2007b; 2009; 2010a; 2010b, 2010c; 2013) e dialogando com estas preocupações - a partir do ponto de vista das discussões resultantes da investigação histórica acerca da gramática e da linguagem arquitetônicas adotadas na Bauhaus - que privilegiei como objeto de pesquisa as concepções presentes na linguagem dos Bauhausers para a arquitetura escolar. Tinha naquela proposta uma continuidade das minhas investigações, visto que o componente imagético dos edifícios pensados para fins educacionais, projetados e construídos pelos fundadores da Bauhaus e seus seguidores, tomaram importância nos estudos históricos por sua linguagem modernista. Esta influenciará os discursos de importantes vanguardas de arquitetos espalhados pelo mundo, em especial, os simpatizantes da corrente denominada Estilo Internacional que também atingirá a formação de importantes arquitetos brasileiros.

Ao longo da minha inserção no Programa de Pós-Graduação em Educação, entrelacei aos meus interesses investigativos um conjunto de orientações, intercâmbios e supervisões que me serviram como alavanca para o amadurecimento de minhas próprias ideias e formas de refinamento de procedimentos de pesquisa. As atividades de orientação sob minha responsabilidade nos níveis de pós-doutorado, doutorado, mestrado e graduação testemunharam o meu crescimento intelectual. A experiência, fruto do convívio com diferentes colegas, temas que eles privilegiaram em suas discussões, é responsável por estabelecer entusiasmo constante na formação de novos pesquisadores em História da Educação. ${ }^{1}$ Dentre os temas orientados, todos giraram em torno da categoria cultura escolar, distribuídos nas seguintes tópicas: Fotografias Escolares (LIMA, 2015), Arquitetura Escolar (BROERING, 2014; CORREIA, 2013, 2004; BRAGA, 2009), Instituições Educacionais de Ensino Superior (MARTINS, 2001; ULHÔA CINTRA, 2010), Instituições Educacionais de Ensino Secundário (IWAYA, 2001; VIANNA, 2001; CHORNOBAI, 2002; SOUZA, 2002, 2006; CARVALHO, 2004; STEIN, 2008; FILHO, 2009; ZACHARIAS, 2013), Instituições Educacionais de Ensino Primário (STORTI, 2011; FUCKNER, 2009)

1 Até o ano de 2015, foram concluídas sob a minha orientação: 37 (trinta e sete) pesquisas de Iniciação Científica, 15 (quinze) de mestrado, 07 (sete) de doutorado e 02 (duas) de pós-doutorado. 
e Instituições Educacionais de Ensino Profissionalizante (COLOMBO, 2002; RIBEIRO, 2012; FREITAS, 2011; SILVEIRA, 2009).

Certamente o meu fascínio pela pesquisa histórica foi paulatinamente intensificado à medida que assumia novos compromissos em investigações nas quais estive diretamente envolvido como coordenador, mas também como pesquisador associado e consultor, sempre preocupado em divulgá-las por meio de publicações ${ }^{2}$ e apresentações de resultados em congressos nacionais e internacionais. ${ }^{3}$ Nesse percurso não diminuo, evidentemente, a importância das pesquisas de mestrado e doutorado; contudo, a experiência com grupos de pesquisa integrados foi responsável por incrementar ainda mais a minha experiência e o meu amadurecimento com o trabalho em equipe. Assim foi que a minha primeira participação dessa natureza aconteceu na segunda metade da década de 1990, quando atuei como pesquisador associado do grupo capitaneado pela Prof. ${ }^{a}$ Dr. ${ }^{a}$ Zeila Brito Fabri Dermatini nas dependências do Centro de Memória da Unicamp, em projeto financiado pela FAPESP intitulado: A diversidade das propostas educacionais na região de Campinas (1859-1960). ${ }^{4} \mathrm{O}$ constante intercâmbio de ideias com pesquisadoras desse grupo, tais como, Rosa Fátima de Sousa e Rosa Lydia Teixeira Correa, amigas e companheiras até hoje de publicações e parcerias acadêmicas, proporcionaram-me conhecer, já naquela época, novas possibilidades de pesquisa, em especial aquelas relacionadas às fotografias escolares. Lembro que essa temática me levou a ser bolsista produtividade do CNPq quando tive a oportunidade de aprofundar meu olhar nas fotografias que registraram os diversos momentos da memória construída dos grupos escolares curitibanos durante a primeira metade do século XX.

2 A minha produção intelectual desde que ingressei na Universidade Federal do Paraná até a defesa de meu memorial está distribuída pelos seguintes produtos bibliográficos: 13 artigos publicados em periódicos, 04 traduções de artigos publicados em periódicos, 21 capítulos de livros publicados, 23 trabalhos completos publicados em anais de congressos, 28 resumos publicados em anais de congressos, 05 edições de livros publicados, 23 edições de periódicos científicos, 02 organizações de cadernos de resumos de eventos, 04 prefácios de livros e 17 prefácios de periódicos.

3 Dentre as dezenas de participações em congressos acadêmicos, destaco aqueles que tenho como importantes propagadores de minhas pesquisas ao longo de décadas, tais como: II, III, V, VI, VIII e IX Congressos Brasileiros de História da Educação; VI, VII, IX e X Congressos Luso-Brasileiros de História da Educação; IV, V, VII, VIII e IX Congressos Iberoamericanos de História da Educação Latinoamericana; XX e XXII Simpósios Nacionais de História da ANPUH; II e IV Seminários de Pesquisa em Educação da Região Sul - ANPED SUL; Internationaler Kongress. Das Jahrhundert der Schule; XV International Symposium on School Life and School History Museums \& Collections; XXV Congrès de 1'Association Internacionelle d Histoire de l'Education; XXII Reunião Anual da Associação Nacional de Pós-Graduação e Pesquisa em Educação e XI Jornadas de Historia de la Educación.

4 Um dos frutos dessa pesquisa é o livro BENCOSTTA, M. L.; DEMARTINI, Z. B. F. et al. (1999). 
Uma das etapas daquele desafio foi minha necessidade de construir narrativas que contribuíssem na construção de sentidos históricos capazes de problematizar a manifestação da cultura no ambiente escolar. Frente inúmeras possibilidades que as fotografias disponibilizam à pesquisa, investi naquelas que tornavam viáveis entender, por exemplo, a manifestação da cultura cívica presente nos desfiles patrióticos enquanto transmissora de "uma linguagem coletiva, capaz de expressar concomitantemente múltiplos planos simbólicos que os levam a ser identificados como uma grande festa" (BENCOSTTA, 2006, p. 300). Mas percebi, por maior que fosse a diversidade de possibilidades, detinha maior tempo de observação em cenas que envolviam a arquitetura e o espaço dos edifícios.

Tornei-me, portanto, um aficionado pela história da arquitetura escolar brasileira, especializando-me neste tema a cada investida alcançada. Dentre as quais, o estágio de pós-doutoramento que realizei na França, onde confirmei pelo manuseio de fontes histórias e patrimoniais da arquitetura da III República francesa referências seguras da adoção desta gramática pela escola primária pública brasileira dos primeiros decênios do século XX. Fruto deste intercâmbio, fundei na Universidade Federal do Paraná, o Núcleo de Estudos e Pesquisas em História da Arquitetura Escolar (NEPHArqE), espaço que pude aglutinar o conjunto de minhas pesquisas e orientações, estabelecendo parcerias com grupos semelhantes na França, Espanha, Portugal, Canadá e México. A partir do acúmulo de uma experiência investigativa de 10 anos sobre a arquitetura escolar, um novo desafio abrigou meu interesse, desta vez por investigar as vanguardas da arquitetura moderna da segunda metade do século XX, em especial a influência da Bauhaus nos edifícios destinados ao uso educacional, tais como, bibliotecas, escolas, universidades e casas de estudantes, que representa o meu atual projeto individual de pesquisa registrado no CNPq. Foi graças a este percurso que, recentemente, foi possível nos anos de 2011 e 2015 estabelecer parcerias com a Universidade de Tel Aviv e a Universidade Hebraica de Jerusalém, onde tive a oportunidade de atuar como professor visitante em ambas as instituições israelenses.

Para além da minha função de orientador, também em meus próprios escritos fui fortemente persuadido pelas discussões em torno dessa categoria. Foram bem marcantes as ideias e as teorias defendidas por Jean-Claude Forquin (1989), Guy Vincent (1994), Dominique Julia (1995), André Chervel (1998), dentre outros. Mas declaro que estive de modo mais próximo às teorias de Antonio Viñao e Escolano (1998), com quem estabeleci uma profícua amizade entre trocas de experiências de pesquisa e publicações em conjunto. Foi influenciado por sua sensibilidade reflexiva que me levou a compreender com outros olhares a escola e suas intermediações com noções que vinculam seus objetos, em especial, a arquitetura que a abriga em espaços e tempos históricos específicos. 
Quando realizamos um estudo comparativo que tratou da historiografia espanhola e brasileira sobre o espaço escolar (BENCOSTTA; VIÑAO, 2009), ${ }^{5}$ apresentamos algumas questões metodológicas que acredito ainda serem válidas para os dias de hoje. Tratava-se de questões que ainda não haviam tido enfoques aprofundados que pudessem contribuir na orientação de nossas futuras investigações sobre as arquiteturas escolares.

Uma dessas questões é o desafio de pesquisas sobre as mutações do espaço projetado pelos arquitetos, aquele que foi prescrito em seus escritórios e pranchas, com o realizado, qual seja, o construído e o vivido, aquele que se transforma em experiência subjetiva em função dos seus usuários ao longo de diferentes tempos. O que demanda um enorme esforço no uso de fontes diversificadas, como, por exemplo: relatórios ou desenhos sobre temas escolares; fotografias; memórias das instituições educacionais; plantas arquitetônicas; informes dos órgãos oficiais; memórias de professores e alunos; gravuras, objetos materiais etc.

Também tínhamos como fundamentais questões que procuram explicar a configuração das disposições do espaço escolar pelos sujeitos que dele fazem uso, sendo necessário, portanto, estudos de suas estruturas morfológicas, físicas e simbólicas, frente às funções a que estavam destinadas, e deles extrair interpretações acerca das relações existentes entre os diversos espaços de uma mesma instituição educacional. Assim, destacávamos a importância de articulação desse espaço escolar como um campo onde estavam intercruzados aspectos materiais e sociais em um movimento que considerava suas faces interna e externa, aberta e fechada.

Outro felicíssimo encontro que tive em minha carreira foi com a colega Anne-Marie Châtelet. Com ela soube entender aspectos no mundo da pesquisa antes despercebidos nesse campo da investigação. Como ela destaca

[...] essa micro-história permite abordar com precisão as relações entre os diversos atores que estão por detrás desta arquitetura, no intuito de entender o que na escala de estudo de uma cidade ou país permanece inacessível. Ela permite compreender uma realidade que escapa aos estudos institucionais. Isso me parece um caminho a seguir, mas não é o único. (BENCOSTTA; CHÂTELET, 2011a, p. 219).

5 Esta pesquisa foi apoiada pelo Ministério da Educação e Ciência do Reino da Espanha (Projeto de pesquisa SEJ 2004-07268/EDUC) e Ministério da Ciência e Tecnologia do Brasil (Edital Universal do CNPQ, processo $\mathrm{n}^{\circ} 474502 / 2006-6$ ). 
Além da escrita acadêmica, outra forma de abordar o tema da arquitetura escolar se deu pelas exposições de artefatos, desenhos, cartões postais, fotografias e maquetes dos edifícios que desafiavam as minhas inquietações de historiador. Dentre aquelas que fui curador e/ou organizador destacaria, em especial: "Lugares de Memória": Arquitetura da Escola Primária Curitibana (1903-1928), ${ }^{6}$ talvez a minha preferida.

Após retorno do estágio de pós-doutoramento na França, reuni um conjunto de fontes de diversos acervos, a partir do qual foi possível a exposição de cartões postais intitulada: "Lugares de Memória": o exemplo da arquitetura escolar francesa. ${ }^{7}$ Também com enfoque na cultura escolar, inclusa a arquitetura dos edifícios escolares, incluo nos destaques as seguintes instalações: Imagens do universo escolar na Curitiba do Século $X X^{8}$; com uma abordagem mais ampliada, juntamente com Rosa Fátima de Souza, organizei duas exposições: a primeira, Cenas e retratos da Escola Primária Brasileira (1930-1960) ${ }^{9}$ e, a segunda, Memórias e Imagens da Escola Primária no Brasil (1930-1960) ${ }^{10}$.

No ano de 2013, ampliei o uso de novas linguagens que para mim continua sendo um grande desafio para a divulgação dos resultados de pesquisas na História da Educação. Trata-se da produção de documentários capaz de transmitir conteúdos da investigação acadêmica. A primeira e ainda única experiência que tive nesse sentido foi compartilhada com o professor Ederson Santos Lima e o diretor Maurício Baggio, juntos produzimos o documentário "Entre fotografias e tinteiros..." (BENCOSTTA; LIMA; BAGGIO, 2013). ${ }^{11}$ Este documentário trata de um primoroso registro de memória de personagens que, ao serem provocados por um conjunto de fotografias, descortinam emocionantes memórias

6 Este trabalho foi aprovado para ser exposto nos seguintes eventos: VIII Congresso Luso-Brasileiro de História da Educação (São Luis, 2010); XXIII Semana de Pesquisa, Ensino e Extensão do Setor de Educação da Universidade Federal do Paraná (Curitiba, 2011), nessa edição foi possível realizar um registro fílmico da exposição que se encontra no seguinte endereço: https:// www.youtube.com/watch?v=YVHFWJK7Zu0; 10 ANPED Sul (Florianópolis, 2014).

7 Exposição organizada em parceria com Marina Fernandes Braga exposta no II Encontro de Arquivos Escolares e Museus Escolares (Curitiba, 2008).

8 Este trabalho foi selecionado para ser exposto nos seguintes eventos: VI Congresso Luso-Brasileiro de História da Educação (Uberlândia, 2006); Semana de Estudos da Pedagogia da Universidade Federal do Paraná (Curitiba, 2006); $28^{\text {a }}$ Reunião Anual da ANPED (Caxambu, 2005); II Seminário de Pesquisa sobre Cultura Escolar: perspectivas históricas (Curitiba, 2005).

9 Inserida na programação cultural do VII Congresso Brasileiro de História da Educação (Goiânia, 2013) e na 35ª Reunião Anual da ANPED (Porto de Galinhas, 2012).

10 Selecionada para ser exposta na $10^{\mathrm{a}}$ Reunião da ANPED Sul (Florianópolis, 2014).

11 Selecionado para a edição do $7^{\circ}$ Festival de Cinema (Lapa - PR, 2014) e para compor a exposição "Glück: o tempo e a imagem", curadoria de Ederson Santos Lima e Graça Bandeira (Museu Oscar Niemeyer, 10/2015-02/2016). A íntegra do documentário é de livre acesso no seguinte endereço: https://www.youtube.com/watch?v=5Dndt_8Qg2M. 
de seu tempo de escola. $\mathrm{O}$ documentário tem relação com a tese de doutorado de autoria do prof. Ederson (LIMA, 2015), que contou com minha orientação.

Reconheço que as atividades extensionistas que desenvolvi foram tímidas diante da importância que elas possuem para o ambiente universitário e sua relação com a sociedade. Oportunidades para coordenar ou participar de projetos de extensão foram inúmeros, muito em decorrência do investimento dessa natureza que desenvolve há décadas o departamento onde estou lotado.

Mas dentre algumas atividades extensionistas que tive a oportunidade de desenvolver na universidade e que me proporcionaram muita satisfação estão relacionadas com a temática dos Direitos Humanos e sua interface com a Educação. A primeira foi quando coordenei, em 2011, o curso de extensão Direitos Humanos em Educação, ofertado pela Coordenação de Integração de Políticas de Educação à Distância da Universidade Federal do Paraná, direcionado à capacitação de educadores e professores do ensino fundamental e médio e outros profissionais e estudantes, além de lideranças comunitárias. A segunda, ainda em andamento em 2015, é a minha contribuição como professor formador do módulo II (Pobreza, Direitos Humanos, Justiça e Educação) do curso de pós-graduação lato sensu em Educação, Pobreza e Desigualdade Social, vinculado à Secretaria de Educação Continuada, Alfabetização e Inclusão do Ministério da Educação (SECADI/MEC). Este tem como objetivo, dentre outros, capacitar profissionais da educação básica e sujeitos envolvidos com políticas sociais que estabelecem relações com a educação em contextos empobrecidos, com vistas à reflexão sobre o desenvolvimento de práticas que possibilitem a transformação das condições de pobreza e de extrema pobreza de crianças, adolescentes e jovens. Gostaria de ter me dedicado muito mais nessa atividade tão importante para a minha formação e carreira. Lamento não ter sido mais aficionado como muitos de meus colegas que se dedicam nessa tarefa que é a extensão universitária.

Durante minha carreira na UFPR, o foco de maior ênfase de minha atuação foi, sem dúvida, direcionado para projetos de ensino e pesquisa, e de menor atuação em atividades extensionistas. No ensino, desde o meu ingresso na UFPR, tenho ministrado as seguintes disciplinas na graduação do curso de Pedagogia: História da Educação Geral, História da Educação no Brasil, História da Arquitetura Escolar (optativa) e História e Cinema (optativa). Na Linha de Pesquisa História e Historiografia da Educação do Programa de Pós-Graduação em Educação da UFPR, tenho ofertado regularmente as seguintes disciplinas: Seminário Avançado de Pesquisa em História e Historiografia da Educação I; Seminário Avançado de Pesquisa em História e Historiografia da Educação II; Seminário Avançado de Pesquisa em História e Historiografia da Educação III; Seminário de Pesquisa em História e Historiografia da Educação I; Seminário de Pesquisa em História e Historiografia da Educação II; Seminário de Pesquisa em 
História e Historiografia da Educação III; Fotografia e Educação: possibilidades de pesquisa histórica; História das Instituições Educacionais no Brasil e, por fim, Patrimônio Educativo e Cultura Material Escolar.

Desde o início da minha carreira docente na UFPR, meu compromisso com o ensino de graduação esteve concentrado no curso de Pedagogia, ofertando as disciplinas obrigatórias e optativas sobre História da Educação Geral e Brasileira que compõem sua grade curricular. Também tive a experiência de ofertar essas mesmas disciplinas para o curso de Pedagogia modalidade a distância para alunos dos polos de Paranaguá (PR), Colombo (PR), Rio Negro (PR), Barretos (SP) e Peruíbe (SP). Em ambas as atuações, frente à importância que o ensino de graduação possui na formação de profissionais capacitados, sempre tive o cuidado de estabelecer uma relação de parceria na construção do conhecimento com meus alunos e alunas na compreensão deste objetivo. Já o ensino de pós-graduação foi consequência do compromisso assumido anteriormente na graduação, de modo que a mesma preocupação com a formação de mestres e doutores em educação, eu tive na formação de professores e pedagogos. Externo à minha instituição de origem, atuei como professor em cursos de pós-graduação da Universidade do Estado de Santa Catarina (SC), Universidade Tiradentes (SE), Universidade de Tel Aviv (Israel) e Universidade Hebraica de Jerusalém (Israel).

Como parte significativa de minhas tarefas como pesquisador é que, desde o início de minha carreira, estive constantemente envolvido em atividades editoriais ou de arbitragem de produção intelectual. No que diz respeito à esfera de editoração de artigos científicos, estive envolvido com periódicos na condição de membro de seu comitê editorial, como, por exemplo, o da revista de História da Educação, vinculada com a Associação Sul-Rio-Grandense de Pesquisadores em História da Educação (ASPHE); da Revista Brasileira de História da Educação, administrada pela Sociedade Brasileira de História da Educação (SBHE); da Revista Brasileira de Educação, periódico da Associação Nacional de Pós-Graduação e Pesquisa em Educação (ANPED) e da Revista Educação da Pontifícia Universidade Católica do Rio Grande do Sul (PUCRS). Também fui consultor regular na revisão de artigos de várias outras revistas do campo da Educação, História e Antropologia Visual.

Também não podia deixar de contribuir com diversas consultorias para os principais órgãos de fomento à pesquisa do país, tais como: Conselho Nacional de Desenvolvimento Científico e Tecnológico - CNPq; Coordenação de Aperfeiçoamento Pessoal de Nível Superior - CAPES; Fundação Araucária - FA; Fundação de Amparo à Pesquisa do Estado de São Paulo - FAPESP; Fundação de Amparo à Pesquisa do Estado de Santa Catarina - FAPESC; Fundação de Amparo à Pesquisa do Estado do Rio de Janeiro - FAPERJ; Fundação de Amparo à Pesquisa do Estado de Minas Gerais - FAPEMIG; Fundação de Amparo 
à Pesquisa do Estado de Sergipe - FAPES; Fundação de Amparo à Pesquisa do Estado do Piauí - FAPEPI; Fundação Fullbright; Conseil International des Études Canadiennes - CIEC e SciELO - Scientific Electronic Library Online.

$\mathrm{Na}$ organização de eventos acadêmicos, sempre que possível priorizei aqueles que estavam próximos às discussões que tínhamos na rede de pesquisa em que estava envolvido, juntamente com outros colaboradores. Foram inúmeros colóquios, simpósios e congressos de grande, médio e pequeno porte que, sem descriminá-los, faço uma pequena apresentação: X Congresso Luso Brasileiro de História da Educação (Curitiba, 2014); 36a Reunião Nacional da ANPEd (Porto de Galinhas, 2013); 35 Reunião Nacional da ANPEd (Goiânia, 2012); II Seminário de Pesquisa sobre Cultura Escolar: perspectivas históricas (Curitiba, 2005); XV Semana de Ensino, Pesquisa e Extensão do Setor de Educação (Curitiba, 2000); I Festival da Universidade Federal do Paraná (2000) e a XV Semana de Ensino, Pesquisa e Extensão do Setor de Educação (Curitiba, 1999).

\section{Considerações finais}

Este instantâneo de minhas memórias acadêmicas fez-me recordar dos bons tempos dos bancos universitários, ainda na época de minha graduação, da consciência e o desejo de seguir a carreira docente, profissão que abracei sem qualquer tipo de arrependimento por menor que tenha sido. Destaco que, durante toda a minha formação e desenvolvimento da carreira, tem sido relevante a importância das bolsas e grants que recebi ao longo dos anos para o meu aprimoramento como professor e pesquisador. Foi assim, desde a minha Iniciação Científica até o meu estágio de pós-doutoramento, como também atividades de professor visitante no Brasil e no exterior, participação em congressos, simpósios etc. Portanto, o financiamento das agências de fomento - como FAPESP, Fundação Araucária, CAPES e CNPq - foram essenciais para o meu refinamento profissional e intelectual.

Por fim, para encerrar este documento, tenho a necessidade de declarar que dentre milhões de brasileiros, obtive como poucos a oportunidade de concluir todos os meus estudos superiores no sistema público de ensino (graduação, mestrado e doutorado); e, como servidor público federal, é uma satisfação retribuir esse investimento na formação de professores, educadores e pesquisadores. 


\section{REFERÊNCIAS}

BENCOSTTA, M. L. Arquitetura e espaço escolar: reflexões acerca do processo de implantação dos primeiros grupos escolares de Curitiba (1903-1928). Educar em Revista, Curitiba, n. 18, p. 103-141, 2001.

BENCOSTTA, M. L. Arquitetura e espaço escolar: o exemplo dos primeiros grupos escolares de Curitiba (1903-1928). In: BENCOSTTA, M. L. (Org.). História da Educação, Arquitetura e Espaço Escolar. São Paulo: Cortez Editora, 2005. p. 141-170.

BENCOSTTA, M. L. O Instituto Nacional de Estudos Pedagógicos (Inep) e o Centro de Estudos e Pesquisas Educacionais (Cepe): a experiência de um laboratório de ensino primário no Paraná (1952-1964). In: ARAÚJO, M.; BRZEZINSKI, I. (Org.). Anísio Teixeira na direção do Inep: Programa para a Reconstrução da Nação Brasileira (19521964). Brasília: Inep, 2006a. p. 51-73.

BENCOSTTA, M. L. Desfiles patrióticos: Memória e cultura cívica dos grupos escolares de Curitiba (1903-1971). In: VIDAL, D. G. (Org.). Grupos Escolares: cultura escolar primária e escolarização da infância no Brasil (1893-1971). Campinas: Mercado de Letras, 2006b. p. 299-321.

BENCOSTTA, M. L. Arquitetura Escolar na Belle Époque: Jean Omer Marchand e Francisco de Paula Ramos de Azevedo (Montreal e São Paulo, 1894-1926). In: BENCOSTTA, M. L. (Org.). Culturas Escolares, Saberes e Práticas Educativas: itinerários históricos. São Paulo: Cortez, 2007a. p. 103-128.

BENCOSTTA, M. L. Desafios da Arquitetura Escolar: construção de uma temática em História da Educação. In: OLIVEIRA, M. A. T. de. (Org.). Cinco estudos em História e Historiografia da Educação. Belo Horizonte: Autêntica, 2007b. p. 111-125.

BENCOSTTA, M. L. Análise da Violência, Indisciplina e Educação: contribuições da Arquitetura. In: HENNING, L. M. P.; ABBUD, M. L. M. (Org.). Violência, indisciplina e educação. Londrina: Editora da UEL, 2010a. p. 155-162.

BENCOSTTA, M. L. A Cultura Escolar na Historiografia da Educação Brasileira: alcances e limites de um conceito. In: FELGUEIRAS, M. L.; VIEIRA, C. E. (Org.). Cultura Escolar, Migrações e Cidadania. Porto: Sociedade Portuguesa de Ciências da Educação, 2010b. p. 10-25.

BENCOSTTA, M. L. Olhares sobre a Cultura Material: discurso arquitetural eclético de Cândido Ferreira de Abreu, um construtor de espaços e ideias na Belle Époque curitibana. In: ENS, R. T.; BEHRENS, M. A. (Org.). Formação do Professor: profissionalidade, pesquisa e cultura escolar. Curitiba: Editora Champagnat, 2010c. p. 239-260.

BENCOSTTA, M. L. Tempos de Jardim de Infância: anos incríveis de uma andorinha em movimento. In: FISCHER, B. T. D. (Org.). Tempos de Escola. Memórias. São Leopoldo: Oikos/Brasília: Liber Livro, 2011. p. 179-192. 
BENCOSTTA, M. L. Mobiliário escolar francês e os projetos vanguardistas de Jean Prouvé e André Lurçat na primeira metade do século XX. Educar em Revista, Curitiba, n. 49, p. 19-38, jul./set. 2013.

BENCOSTTA, M. L.; DEMARTINI, Z. B. F. et al. Memórias da Educação - Campinas (1860-1950). Campinas: Editora da Unicamp, 1999.

BENCOSTTA, M. L.; LIMA, E. P. S.; BAGGIO, M. Entre tintas e tinteiros... Curitiba, Produtora Zoom, 2013.

BENCOSTTA, M. L.; CHÂTELET, A. M. Diálogos sobre a História da Arquitetura Escolar. Linhas, v. 12, p. 210-219, 2011 a.

BENCOSTTA, M. L.; BRAGA, M. F. História e Arquitetura Escolar: a experiência dos regulamentos franceses e brasileiros para os edifícios escolares (1880-1910). Linhas, v. 12 , p. 51-72, 2011 b.

BENCOSTTA, M. L.; CORREA, A. P. P. Arquitetura moderna e espaços modelares para as práticas esportivas em ambiente escolar: o exemplo do Colégio Estadual do Paraná (Curitiba, 1943-1950). Linhas, v. 12, p. 95-110, 2011c.

BENCOSTTA, M. L.; VIÑAO, A. Entre a multidisciplinariedade e a história: o espaço e a arquitetura escolares nas recentes historiografias educativas espanhola e brasileira. In: ARAÚJO, M. M. de. (Org.). História Comparada da Educação. 1. ed. Natal: Editora da UFRN; Brasília: Liber Livro Editora, 2009. p. 23-51.

BOERING, A. de S. Arquitetura, espaços, tempos e materiais: a educação infantil na Rede Municipal de Ensino de Florianópolis (1976-2012). 2014. Dissertação (Mestrado em Educação) - Universidade do Estado de Santa Catarina, Florianópolis, 2014. (Co-orientador).

BOUDON, P. Enseigner la conception architecturale: cours d'architecturologie. Paris: Éd. de la Villette, 2001.

BOUDON, P. Sur l'espace architectural. Essai d'épistémologie de l'architecture. Nouvelle édition revue et augmentée. Marseille: Parenthèses, 2003.

BRAGA, M. F. Arquitetura e Espaço Escolar na Atenas Mineira: os Grupos Escolares de Juiz de Fora (1907-1927). 2009. Dissertação (Mestrado em Educação) - Universidade Federal do Paraná, Curitiba, 2009.

CARVALHO, F. C. de P. e S. Igreja Católica e Educação Feminina: a Escola Normal do Colégio Sagrado Coração de Jesus (Canoinhas-SC, 1936-1956). 2004. Dissertação (Mestrado em Educação) - Universidade Federal do Paraná, Curitiba, 2004.

CHERVEL, A. La culture scolaire. Une approche historique. Paris: Belin, 1998.

CHORNOBAI, G. Q. L. Igreja Católica, Educação Feminina e Cultura Escolar em Ponta Grossa (Paraná): a Escola Normal de Sant’Ana (1947-1960). 2002. Dissertação (Mestrado em Educação) - Universidade Federal do Paraná, Curitiba, 2002. 
COLOMBO, I. $O$ adolescente infrator e o sistema de ensino paranaense: a trajetória da Escola para menores Professor Queiroz Filho (1965-1992). 2002. Dissertação (Mestrado em Educação) - Universidade Federal do Paraná, Curitiba, 2002.

CORREIA, A. P. P. História \& Arquitetura Escolar: os prédios escolares públicos de Curitiba (1943-1953). 2004. Dissertação (Mestrado em Educação) - Universidade Federal do Paraná, Curitiba, 2004.

CORREIA, A. P. P. "Palácios da Instrução" - História da Educação e Arquitetura das Escolas Normais no Estado do Paraná (1904-1927). 2013. Tese (Doutorado em Educação) - Universidade Federal do Paraná, Curitiba, 2013.

FILHO, R. C. São José, o Colégio de Castro (1904-1994). 2009. Tese (Doutorado em Educação) - Universidade Federal do Paraná, Curitiba, 2009.

FORQUIN, J.-C. Ecole et culture. Le point de vue des sociologues britanniques. Bruxelles: Boeck-Editions Universitaires, 1989.

FREITAS, D. G. de. Entre oficios e prendas domésticas: a Escola Profissional Feminina de Curitiba (1917-1974). 2011. Dissertação (Mestrado em Educação) - Universidade Federal do Paraná, Curitiba, 2011.

FUCKNER, C. M. Lar Escola Dr. Leocádio José Correia: história de uma proposta de formação na perspectiva educacional espírita (1963-2003). 2009. Tese (Doutorado em Educação) - Universidade Federal do Paraná, Curitiba, 2009.

IWAYA, M. Palácio da Instrução: Representações sobre o Instituto de Educação do Paraná Professor Erasmo Pilotto (1940-1960). 2001. Dissertação (Mestrado em Educação) - Universidade Federal do Paraná, Curitiba, 2001.

JULIA, D. La culture scolaire comme objet historique. Paedagogica Historica. International Journal of the History of Education (Suppl. Series), v. I, p. 353-382, 1995. Coord. A. Nóvoa, M. Depaepe e E. V. Johanningmeier.

LIMA, E. P. S. História, Memória e Educação no olhar photographico de Guilherme Glück (Lapa, 1920-1953). 2015. Tese (Doutorado em Educação) - Universidade Federal do Paraná, Curitiba, 2015.

MARTINS, E. Marginalidade, implantação e reconhecimento formal: aspectos históricos de um olhar protestante sobre a Teologia Superior no Brasil (1969-1999). 2001. Dissertação (Mestrado em Educação) - Universidade Federal do Paraná, Curitiba, 2001.

RIBEIRO, I. "Sem uniforme não entra": o uniforme escolar na Escola Técnica Federal de Santa Catarina (1962-1983). 2012. Dissertação (Mestrado em Educação) - Universidade do Estado de Santa Catarina, Florianópolis, 2012. (Co-orientador).

SILVEIRA, M. H. P. O Processo de normalização do comportamento social em Curitiba: Educação e Trabalho na Penitenciária do Ahú na primeira metade do século XX. 2009. Tese (Doutorado em Educação) - Universidade Federal do Paraná, Curitiba, 2009. 
STEIN, C. A. "Por Deus e pelo Brasil": a Juventude Brasileira em Curitiba (19381945). 2008. Dissertação (Mestrado em Educação) - Universidade Federal do Paraná, Curitiba, 2008.

STORTI, W. M. R. Educação Árabe em Curitiba: a Escola Islâmica do Paraná (19691972). 2011. Dissertação (Mestrado em Educação) - Universidade Federal do Paraná, Curitiba, 2011.

SOUZA, R. M. S. de. A Estrada do Poente: Escola Alemã/Colégio Progresso (Curitiba 1930-1945). 2002. Dissertação (Mestrado em História) - Universidade Federal do Paraná, Curitiba, 2002. (Co-orientador).

SOUZA, R. M. S. de. Deutsche Schule, a Escola Alemã de Curitiba (1884-1917): um olhar histórico. 2006. Tese (Doutorado em Educação) - Universidade Federal do Paraná, Curitiba, 2006.

ULHÔA CINTRA, E. P. de. "Sciencia et Labor" no "Palácio de Luz": a institucionalização da Ciência Médica e a Faculdade de Medicina do Paraná (Curitiba, 1912-1946). 2010. Tese (Doutorado em Educação) - Universidade Federal do Paraná, Curitiba, 2010.

VIANNA, G. de S. O Sabre e o Livro: Trajetórias Históricas do Colégio Militar de Curitiba (1959-1988). 2011. Dissertação (Mestrado em Educação) - Universidade Federal do Paraná, Curitiba, 2001.

VIÑAO, A.; ESCOLANO, A. Currículo, espaço e subjetividade. A arquitetura como programa. Rio de Janeiro: DP\&A Editora, 1998.

VINCENT, G. (Org.). L'Éducation prisonnière de la forme scolaire? Scolarisation et socialisation dans les societies industrielles. Lyon: Presses Universitaires de Lyon, 1994. p. 11-48.

ZACHARIAS, M. R. Espaços e processos educativos do Ginásio Paranaense. Os ambientes especializados e seus artefatos (1904-1949). 2013. Dissertação (Mestrado em Educação) - Universidade Federal do Paraná, Curitiba, 2013.

Texto recebido em 17 de maio de 2018. Texto aprovado em 31 de maio de 2018. 
